\title{
O CÔNEGO OU METAFÍSICA DO ESTILO, CONTO DE MACHADO DE ASSIS: UMA TRADUÇÃO COMENTADA
}

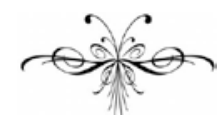

MACHADO DE AsSIS

CÁSSIA SigLE

Marcus Tulius Franco Morais

\section{O CÔNEGO OU \\ METAFÍSICA DO ESTILO}

- "Vem do Líbano, esposa minha, vem do Líbano, vem... As mandrágoras deram o seu cheiro. Temos às nossas portas toda a casta de pombos...”

— "Eu vos conjuro, filhas de Jerusalém, que se encontrardes o meu amado, lhe façais saber que estou enferma de amor...”

Era assim, com essa melodia do velho drama de Judá, que procuravam um ao outro na cabeça do Cônego Matias um substantivo e um adjetivo... Não me interrompas, leitor precipitado; sei que não acreditas em nada do que vou dizer. Di-lo-ei, contudo, a despeito da tua pouca fé, porque o dia da conversão pública há de chegar.

\section{DER DOMHERR ODER METAPHYSIK DES STILS}

- „Komm mit mir vom Berge Libanon, meine Braut, komm mit mir vom Libanon, komm... Die Alraunen geben Duft, und an unseren Türöffnungen allerlei Tauben ...”

- „Ich beschwöre Euch, Ihr Töchter Jerusalems, findet Ihr meinen Geliebten, so sagt ihm, dass ich vor Liebe krank liege..."

Und so war es, wie die Melodie des alten Dramas von Judäa, dass sie einander suchten im Kopfe des Domherrn Matias, ein Substantiv und ein Adjektiv ... Unterbrich mich nicht, voreiliger Leser; mir ist bewusst, dass Du dem, was ich sagen werde, keinen Glauben schenkst. Dennoch werde ich es Dir sagen, trotz Deiner Kleingläubigkeit, denn es wird kommen der Tag der öffentlichen Bekehrung. 
Nesse dia, - cuido que por volta de 2222, — o paradoxo despirá as asas para vestir a japona de uma verdade comum. Então esta página merecerá, mais que favor, apoteose. Hão de traduzi-la em todas as línguas. As academias e institutos farão dela um pequeno livro, para uso dos séculos, papel de bronze, corte-dourado, letras de opala embutidas, e capa de prata fosca. Os governos decretarão que ela seja ensinada nos ginásios e liceus. As filosofias queimarão todas as doutrinas anteriores, ainda as mais definitivas, e abraçarão esta psicologia nova, única verdadeira, e tudo estará acabado. Até lá passarei por tonto, como se vai ver.

Matias, cônego honorário e pregador efetivo, estava compondo um sermão quando começou o idílio psíquico. Tem quarenta anos de idade, e vive entre livros e livros para os lados da Gamboa. Vieram encomendar-lhe o sermão para certa festa próxima; ele que se regalava então com uma grande obra espiritual, chegada no último paquete, recusou o encargo; mas instaram tanto, que aceitou.

- Vossa Reverendíssima faz isto brincando, disse o principal dos festeiros.

Matias sorriu manso e discreto, como devem sorrir os eclesiásticos e os diplomatas. Os festeiros despediram-se com grandes gestos de veneração, e foram anunciar a festa nos jornais, com a declaração de que pregava ao Evangelho o Cônego Matias "um dos ornamentos do clero brasileiro". Este
An diesem Tage - ich schätze um das Jahr 2222 - wird das Paradox seine Flügel ablegen, um den Mantel einer gewöhnlichen Wahrheit $\mathrm{zu}$ tragen. Dann wird diese Seite mehr als Gefallen finden, Vergötterung. In alle Sprachen wird sie übersetzt werden müssen. Die Akademien und Institute werden aus ihr ein kleines Buch anfertigen, über Jahrhunderte anzuwenden, Bronzepapier, Goldschnitt, eingefasste Opal-Wörter und mattsilberner Einband. Die Regierungen werden anordnen, dass sie an Schulen und Gymnasien gelehrt werde. Die Philosophien werden alle bisherigen Doktrinen niederbrennen, auch die endgültigsten, und werden diese neue Psychologie in ihre Arme schließen, als einzig wahre, und alles wird vollendet sein.

Bis dahin werde ich für einen Tor gehalten, wie man sehen wird.

Matias, ehrenhafter Domherr und amtlicher Prediger, war gerade dabei, eine Predigt $\mathrm{zu}$ schreiben, als das psychische Idyll begann. Er ist vierzig Jahre alt und lebt nahe am Gamboaufer, umgeben von Büchern, vielen Büchern. Er war beauftragt worden, die Predigt für ein bestimmtes bevorstehendes Fest zu verfassen; er, der also an einem großen Geisteswerk Gefallen fand, welches mit dem letzten Schiffe gekommen, lehnte den Auftrag $\mathrm{ab}$; doch man bestand solange darauf, dass er sich schließlich dazu überreden ließ.

- Euer Hochwürden macht das mit Leichtigkeit, sagte der Festvorstand. Matias lächelte leicht und zurückhaltend, wie die Geistlichen und Diplomaten wohl eben lachen sollen. Die Festgäste verabschiedeten sich mit Gesten größter Verehrung und gaben unverzüglich das Fest in den Zeitungen bekannt, mit der Ankündigung, dass der Domherr Matias das Evangelium predigen werde, „eine der Zierden des 
“ornamento do clero" tirou ao cônego a vontade de almoçar, quando ele o leu agora de manhã; e só por estar ajustado, é que se meteu a escrever o sermão.

Começou de má vontade, mas no fim de alguns minutos já trabalhava com amor. A inspiração, com os olhos no céu, e a meditação, com os olhos no chão, ficam a um e outro lado do espaldar da cadeira, dizendo ao ouvido do cônego mil coisas místicas e graves. Matias vai escrevendo, ora devagar, ora depressa. As tiras saem-lhe das mãos, animadas e polidas. Algumas trazem poucas emendas ou nenhumas. De repente, indo escrever um adjetivo, suspende-se; escreve outro e risca-o; mais outro, que não tem melhor fortuna. Aqui é o centro do idílio. Subamos à cabeça do cônego.

Upa! Cá estamos. Custou-te, não, leitor amigo? É para que não acredites nas pessoas que vão ao Corcovado, e dizem que ali a impressão da altura é tal, que o homem fica sendo coisa nenhuma. Opinião pânica e falsa, falsa como Judas e outros diamantes. Não creias tu nisso, leitor amado. Nem Corcovados, nem Himalaias valem muita coisa ao pé da tua cabeça, que os mede. Cá estamos. Olha bem que é a cabeça do cônego. Temos à escolha um ou outro dos hemisférios cerebrais; mas vamos por este, que é onde nascem os substantivos. Os adjetivos nascem no da esquerda. Descoberta minha, que, ainda assim, não é a principal, mas a base dela, como se vai ver. Sim, meu senhor, os adjetivos nascem de um lado, e os substantivos de outro, e toda a sorte de vocábulos está assim brasilianischen Klerus”. Diese „Zierde des Klerus" verdarb dem Domherrn den Appetit auf sein Mittagessen, als er das in der Früh las; und nur, weil es schon vereinbart war, ließ er sich doch noch auf die Predigt ein.

Er begann recht lustlos, aber nach einigen Minuten schon arbeitete er mit liebevoller Hingabe. Die Inspiration, die Augen auf den Himmel gerichtet, die Besinnung, die Augen auf den Boden fixiert, sitzen auf der einen und auf der anderen Seite seiner Rückenlehne und flüstern dem Domherrn tausende von mystischen und ernsten Dingen ins Ohr. Matias fährt fort mit dem Schreiben, mal langsam, mal schnell. Die Zeilen schreibt er an einem Stück, lebhaft und glänzend, manche bedürfen weniger Ausbesserungen, oder gar keiner. Plötzlich, als er zu einem Adjektiv ansetzt, zögert er; schreibt ein anderes nieder und streicht es wieder; noch eines, das auch kein besseres Schicksal erfährt. Hier ist der Mittelpunkt des Idylls. Steigen wir hinauf zum Kopfe des Domherrn.

So! Da wären wir. Das war von Mühe, nicht wahr, werter Freund und Leser? Das machen wir, damit Du nicht jenen glaubst, die den Corcovado besteigen und behaupten, man empfinde die Höhe dort dermaßen, dass der Mensch ein Nichts wird. Überstürzte und falsche Ansicht, so falsch wie Judas und andere Diamanten. Glaube das ja nicht, lieber Leser. Weder Corcovados noch Himalayas sind viel wert zu Füßen Deines Kopfes, der sie misst. Da sind wir. Schau genau hin, wie es im Kopfe des Domherrn aussieht. Wir haben die eine oder die andere der Gehirnhälften zur Wahl; aber schauen wir uns diese hier an, in der die Substantive ihren Ursprung haben. Die Adjektive finden in der linken Hälfte ihren Ursprung. Das ist meine Entdeckung, auch wenn 
dividida por motivo da diferença sexual...

\section{- Sexual?}

Sim, minha senhora, sexual. As palavras têm sexo. Estou acabando a minha grande memória psico-léxicológica, em que exponho e demonstro esta descoberta. Palavra tem sexo. outras?

— Mas, então, amam-se umas às

Amam-se umas às outras. E casam-se. O casamento delas é o que chamamos estilo. Senhora minha, confesse que não entendeu nada.

- Confesso que não.

Pois entre aqui também na cabeça do cônego. Estão justamente a suspirar deste lado. Sabe quem é que suspira? é o substantivo de há pouco, o tal que o cônego escreveu no papel, quando suspendeu a pena. Chama por certo adjetivo, que lhe não aparece: "Vem do Líbano, vem..." E fala assim, pois está em cabeça de padre; se fosse de qualquer pessoa do século, a linguagem seria a de Romeu: "Julieta é o sol... ergue-te, lindo sol.” Mas em cérebro eclesiástico, a linguagem é a das Escrituras. Ao cabo, que importam fórmulas? Namorados de Verona ou de Judá falam todos o mesmo idioma, como acontece com o thaler ou o dólar, o florim ou a libra, que é tudo o mesmo dinheiro.

Portanto, vamos lá por essas circunvoluções do cérebro eclesiástico, atrás do substantivo que procura o adjetivo. Sílvio chama por Sílvia. sie nicht die entscheidende ist, jedoch ihre Grundlage, wie man später feststellen wird. Ja, mein Herr, die Adjektive kommen aus der einen und die Substantive aus der anderen Seite, und so sind allerlei Vokabeln aufgrund des Geschlechtsunterschiedes getrennt.

- Geschlechts?

Ja, gnädige Frau, Geschlecht. Die Wörter haben ein Geschlecht. Ich beende gerade meine große psycholexiko-logische Überlegung, in der ich diese Entdeckung entwickle und beweise. Wörter haben ein Geschlecht. einander?

- Aber, dann lieben sie auch

Sie lieben einander. Und heiraten. Ihre Ehe ist das, was wir Stil nennen. Verehrte Dame, geben Sie zu, dass Sie nichts verstanden haben.

- Ja, ich gebe es zu.

So kommen Sie doch auch hier herein in den Kopf des Domherrn. Sie seufzen gerade auf dieser Seite. Wissen Sie, wer da seufzt? Es ist das Substantiv von vorhin, welches der Domherr niedergeschrieben hatte, als er seine Feder absetzte. Es sehnt sich nach einem gewissen Adjektiv, welches ihm nicht erscheint: „Komm mit mir vom Berge Libanon, komm...” Und es spricht so, weil es im Kopfe eines Predigers ist; wenn es hingegen im Kopfe irgendeines Normalsterblichen wäre, dann wäre seine Sprache die Romeos: „Julia ist die Sonne ... geh auf, schöne Sonne”. Im Gehirn eines Geistlichen jedoch ist die Sprache die der Schriften. Aber letztendlich, was bedeuten schon Formeln? Liebespaare aus Verona oder aus Judäa sprechen alle dieselbe Sprache, vergleichbar mit dem Taler oder dem Dollar, dem Gulden oder dem Pfund, was alles dasselbe Geld ist.

Also folgen wir den Irrwegen des Gehirns eines Geistlichen, auf den Spuren des Substantivs, welches das Adjektiv sucht. Sílvio ruft nach Sílvia. 
Escutai; ao longe parece que suspira também alguma pessoa; é Sílvia que chama por Sílvio.

Ouvem-se agora e procuram-se. Caminho difícil e intrincado que é este de um cérebro tão cheio de coisas velhas e novas! Há aqui um burburinho de idéias, que mal deixa ouvir os chamados de ambos; não percamos de vista o ardente Sílvio, que lá vai, que desce e sobe, escorrega e salta; aqui, para não cair, agarra-se a umas raízes latinas, ali abordoa-se a um salmo, acolá monta num pentâmetro, e vai sempre andando, levado de uma força íntima, a que não pode resistir.

De quando em quando, aparecelhe alguma dama - adjetivo também - e oferece-lhe as suas graças antigas ou novas; mas, por Deus, não é a mesma, não é a única, a destinada $a b$ eterno para este consórcio. E Sílvio vai andando, à procura da única. Passai, olhos de toda cor, forma de toda casta, cabelos cortados à cabeça do Sol ou da Noite; morrei sem eco, meigas cantilenas suspiradas no eterno violino; Sílvio não pede um amor qualquer, adventício ou anônimo; pede um certo amor nomeado e predestinado.

Agora não te assustes, leitor, não é nada; é o cônego que se levanta, vai à janela, e encosta-se a espairecer do esforço. Lá olha, lá esquece o sermão e o resto. O papagaio em cima do poleiro, ao pé da janela, repete-lhe as palavras do costume e, no terreiro, o pavão enfuna-se todo ao sol da manhã; o próprio sol, reconhecendo o cônego, manda-lhe um dos seus fiéis raios, a cumprimentá-lo. E o raio vem, e pára diante da janela: "Cônego ilustre, aqui venho trazer os recados do sol, meu
Höret; von weitem scheint auch eine Person zu seufzen; es ist Sílvia, die nach Sílvio ruft.

Nun hören sie sich und suchen sich. Welch ein schwerer und verzwickter Weg ist der eines Gehirns, voll von altem und neuem Zeug! Hier gibt es ein Getuschel von Gedanken, das ihre Rufe kaum erschallen lässt; lassen wir den feurigen Sílvio nicht aus den Augen, der da geht, mal runter mal hoch, rutscht und springt; hier, um nicht $\mathrm{zu}$ fallen, hält er sich an so manchen lateinischen Wurzeln fest, da stützt er sich auf einen Psalm, dort steigt er auf einen fünfsilbigen Vers und reitet immer weiter, von einer inneren Kraft getrieben, welcher er nicht widerstehen kann.

$\mathrm{Ab}$ und an erscheint ihm eine Dame - ebenfalls ein Adjektiv - und bietet ihm ihre alte oder neue Anmut an; aber um Gottes Willen, es ist nicht dieselbe, nicht die einzige, die $a b$ aeterno Bestimmte für dieses Bündnis. Und Sílvio geht umher auf der Suche nach der Einzigen. Gehet vorbei, Augen aller Farben, Formen aller Art, geschnittenes Haar, hin zur Sonne oder zur Nacht; sterbet ohne Widerklang, liebevolle, seufzende Lieder der ewigen Geige; Sílvio wünscht sich nicht irgendeine Liebe, keine zufällige oder namenlose; er wünscht sich eine ganz bestimmte, erwählte und vorherbestimmte Liebe.

Nun erschrecke Dich nicht, lieber Leser, nichts ist geschehen; es ist nur der Domherr, der aufsteht, sich ans Fenster begibt und sich dort anlehnt, um sich von der Anstrengung zu erholen. Dort schaut er ins Leere, dort vergisst er die Predigt und alles Weitere. Der Papagei auf der Sitzstange, am Fenster, wiederholt ihm die gewohnten Wörter, und auf dem Hof zeigt der Pfau sein schillerndes Gefieder in der Morgensonne; selbst die Sonne, die den Domherrn erkennt, 
senhor e pai.” Toda a natureza parece assim bater palmas ao regresso daquele galé do espírito. Ele próprio alegra-se, entorna os olhos por esse ar puro, deixa-os ir fartarem-se de verdura e fresquidão, ao som de um passarinho e de um piano; depois fala ao papagaio, chama o jardineiro, assoa-se, esfrega as mãos, encosta-se. Não lhe lembra mais nem Sílvio nem Sílvia.

Mas Sílvio e Sílvia é que se lembram de si. Enquanto o cônego cuida em coisas estranhas, eles prosseguem em busca um do outro, sem que ele saiba nem suspeite nada. Agora, porém, o caminho é escuro. Passamos da consciência para a inconsciência, onde se faz a elaboração confusa das idéias, onde as reminiscências dormem ou cochilam. Aqui pulula a vida sem formas, os germens, e os detritos, os rudimentos e os sedimentos; é o desvão imenso do espírito. Aqui caíram eles, à procura um do outro, chamando e suspirando. Dê-me a leitora a mão, agarre-se o leitor a mim, e escorreguemos também.

Vasto mundo incógnito. Sílvio e Sílvia rompem por entre embriões e ruínas. Grupos de idéias, deduzindo-se à maneira de silogismos, perdem-se no tumulto de reminiscências da infância e do seminário. Outras idéias, grávidas de idéias, arrastam-se pesadamente, amparadas por outras idéias virgens. Coisas e homens amalgamam-se; Platão traz os óculos de um escrivão da câmara eclesiástica; mandarins de schickt ihm einen ihrer treuen Strahlen und begrüßt ihn. Und der Strahl kommt und hält vor dem Fenster: „Verehrter Domherr, ich überbringe die Botschaften der Sonne, meines Gottes und Vaters”. Die ganze Natur scheint somit seiner Rückkehr aus jenem Geistesaufwand ihren Beifall zu spenden. Er selbst freut sich, schaut ergriffen in die frische Luft, lässt seine Augen satt werden an Natur und Frische, bei Vogelgesang und Klavierspiel; danach spricht er zum Papageien, ruft den Gärtner, putzt sich die Nase, reibt sich die Hände, lehnt sich an. Er erinnert sich weder an Sílvio noch an Sílvia.

Aber Sílvio und Sílvia erinnern sich durchaus aneinander. Während der Domherr sich sonderbaren Dingen widmet, fahren sie fort auf der Suche nach dem jeweils anderen, ohne dass dieser etwas davon weiß oder auch nur vermutet. Jetzt aber ist der Weg dunkel. Wir gehen vom Bewusstsein über zum Unterbewusstsein, wo die verwirrende Gedankenbildung stattfindet, wo die Erinnerungen schlafen oder dahindösen. Hier sprudelt das Leben formlos, die Keime und die Abfälle, die Grundlagen und die Bodensätze; das ist der gewaltige Schlupfwinkel des Geistes. Hier sind sie gestürzt auf der gegenseitigen Suche, als sie riefen und seufzten. Gib mir Deine Hand, meine Leserin, halte Dich fest an mir, mein Leser, so rutschen wir mit.

Weite, unheimliche Welt. Sílvio und Sílvia sprießen zwischen Embrios und Ruinen. Bündel von Ideen, die sich wie Syllogismen ableiten lassen, verlieren sich im Tumult von Erinnerungen an die Kindheit und an die Klosterschule. Andere Ideen, schwanger von Ideen, schleppen sich schwerfällig dahin, gestützt von anderen, jungfräulichen Ideen. Dinge und Menschen werden eins; Platon 
todas as classes distribuem moedas etruscas e chilenas, livros ingleses e rosas pálidas; tão pálidas, que não parecem as mesmas que a mãe do cônego plantou quando ele era criança. Memórias pias e familiares cruzam-se e confundem-se. Cá estão as vozes remotas da primeira missa; cá estão as cantigas da roça que ele ouvia cantar às pretas, em casa; farrapos de sensações esvaídas, aqui um medo, ali um gosto, acolá um fastio de coisas que vieram cada uma por sua vez, e que ora jazem na grande unidade impalpável e obscura.

minha...

- Vem do Líbano, esposa

— Eu vos conjuro, filhas de Jerusalém...

Ouvem-se cada vez mais perto. Eis aí chegam eles às profundas camadas de teologia, de filosofia, de liturgia, de geografia e de história, lições antigas, noções modernas, tudo à mistura, dogma e sintaxe. Aqui passou a mão panteísta de Spinoza, às escondidas; ali ficou a unhada do Doutor Angélico; mas nada disso é Sílvio nem Sílvia. E eles vão rasgando, levados de uma força íntima, afinidade secreta, através de todos os obstáculos e por cima de todos os abismos. Também os desgostos hão de vir. Pesares sombrios, que não ficaram no coração do cônego, cá estão, à laia de manchas morais, e ao pé deles o reflexo amarelo ou roxo, ou o que quer que seja da dor alheia e universal. Tudo isso vão eles cortando, com a rapidez do amor e do desejo.

Cambaleias, leitor? Não é o mundo que desaba; é o cônego que se bringt die Brille eines Schreibers des Kirchenvorstandes; Mandarins aller Klassen verteilen etruskische und chilenische Münzen, englische Bücher und blasse Rosen; so blass, dass sie nicht jenen gleichen, welche die Mutter des Domherrn einst pflanzte, als er ein Kind war. Fromme und vertraute Erinnerungen begegnen sich und verwechseln sich. Da sind die Stimmen von damals, von der ersten Messe; da sind die Volkslieder vom Lande, die er von den schwarzen Frauen hörte, zu Hause; Fetzen geschwächter Empfindungen, hier Angst, da Freude, dort langweilige Dinge, von denen ein jedes nach und nach gekommen, und die nun in der großen, ungreifbaren und finsteren Einheit ruhen.

- Komm mit mir vom Berge Libanon, meine Braut...

- Ich beschwöre Euch, Ihr Töchter Jerusalems...

Sie hören sich immer näher kommen. Genau da gelangen sie zu den tiefen Schichten von Theologie, Philosophie, Liturgie, Geografie und Geschichte, alten Lehren, modernen Erkenntnissen, alles verquickt, Dogma und Syntax. Hier ist Spinozas pantheistische Hand verborgen; dort blieb der Kratzer von Doktor Angelus zurück; aber nichts desgleichen ist Sílvio oder Sílvia. Und sie werden weggezerrt, von einer inneren Kraft fortgerissen, geheimer Verwandtschaft, hindurch allen Hindernissen und über alle Abgründe hinweg. Auch Missfallen wird kommen müssen. Düsterer Kummer, vertrieben aus dem Herzen des Domherrn, ist hier, in Form von moralischen Flecken, und zu ihren Füßen der gelbe oder fliederne Widerschein, oder was auch immer der fremde und universale Schmerz sei. All das werden sie mit der Liebes- und Begehrenseile allmählich lindern.

Schwankst du, Leser? Es ist nicht die Welt, die einstürzt; es ist der 
sentou agora mesmo. Espaireceu à vontade, tornou à mesa do trabalho, e relê o que escreveu, para continuar; pega da pena, molha-a, desce-a ao papel, a ver que adjetivo há de anexar ao substantivo.

Justamente agora é que os dois cobiçosos estão mais perto um do outro. As vozes crescem, o entusiasmo cresce, todo o Cântico passa pelos lábios deles, tocados de febre. Frases alegres, anedotas de sacristia, caricaturas, facécias, disparates, aspectos estúrdios, nada os retém, menos ainda os faz sorrir. Vão, vão, o espaço estreita-se. Ficai aí, perfis meio apagados de paspalhões que fizeram rir ao cônego, e que ele inteiramente esqueceu; ficai, rugas extintas, velhas charadas, regras de voltarete, e vós também, células de idéias novas, debuxos de concepções, pó que tens de ser pirâmide, ficai, abalroai, esperai, desesperai, que eles não têm nada convosco. Amam-se e procuram-se.

Procuram-se e acham-se. Enfim, Sílvio achou Sílvia. Viram-se, caíram nos braços um do outro, ofegantes de canseira, mas remidos com a paga. Unem-se, entrelaçam os braços, e regressam palpitando da inconsciência para a consciência. "Quem é esta que sobe do deserto, firmada sobre o seu amado?”, pergunta Sílvio, como no Cântico; e ela, com a mesma lábia erudita, responde-lhe que "é o selo do seu coração", e que "o amor é tão valente como a própria morte”.

Nisto, o cônego estremece. O rosto ilumina-se-lhe. A pena, cheia de comoção e respeito, completa o substantivo com o adjetivo. Sílvia
Domherr, der gerade Platz nahm. Er hatte sich genügend abgelenkt, kam zurück an den Schreibtisch, und um fortzufahren, liest er nun noch einmal, was er geschrieben hat; er nimmt die Feder, tunkt sie ein, setzt sie aufs Papier und schaut, welches Adjektiv er dem Substantiv anfügen kann.

Gerade jetzt sind sich die beiden Habgierigen etwas näher. Die Stimmen werden lauter, der Enthusiasmus nimmt zu, das ganze Hohelied geht über ihre Lippen, fieberglühend. Heitere Sätze, Sakristrei-Anekdoten, Karikaturen, Scherze, Blödsinn, komische Aspekte, nichts hält sie zurück, und noch weniger bringt sie etwas zum Lachen. Gehet fort, gehet, es wird immer enger. Bleibet da, halb verschwommene Narrenprofile, die den Domherrn zum Lachen brachten und die er völlig vergaß; bleibet, erloschene Falten, alte Silbenrätsel, Schafkopfregeln, und auch Ihr, Zellen neuer Ideen, Konzeptentwürfe, Staub, zur Pyramide verbannt, bleibet, stürzet ein, wartet, verzweifelt, denn sie betreffen Euch nicht. Sie lieben sich und sie suchen sich.

Sie suchen sich und sie finden sich. Endlich: Sílvio fand Sílvia. Sie sahen sich, fielen sich in die Arme, keuchend vor Erschöpfung, jedoch erlöst und entgolten. Sie vereinen sich, umarmen einander und kehren mit klopfendem Herzen vom Unterbewusstsein zurück zum Bewusstsein. „Wer ist die, die heraufsteigt von der Wüste und lehnt sich auf ihren Geliebten?” fragt Sílvio, wie im Hohenlied; und sie, mit demselben gelehrten Mundwerk, antwortet ihm, „Es ist das Siegel Deines Herzens” und „die Liebe ist stark wie der Tod.”

Dabei bebt der Domherr. Sein Gesicht hellt sich auf. Die Feder voller Rührung und Respekt führt Substantiv und Adjektiv zusammen. Sílvia wird 
caminhará agora ao pé de Sílvio, no sermão que o cônego vai pregar um dia destes, e irão juntinhos ao prelo, se ele coligir os seus escritos, o que não se sabe. jetzt gemeinsam mit Sílvio ihren Weg gehen, in der Predigt, die der Domherr eines Tages halten wird, und sie kommen schön beieinander in den Druckstock für den Fall, dass er seine Schriften zusammenstellt, was man nicht wissen kann.

\section{ENDE}

$1 \begin{aligned} & \text { ais uma vez, devemos aos editores da Scientia Traductionis a } \\ & \text { gentileza da autorização que nos permite oferecer ao público leitor } \\ & \text { esta tradução alemã do conto O Cônego ou Metafísica do Estilo, }\end{aligned}$ de Machado de Assis.

Como sempre, Machado de Assis encanta e seduz. Sua prosa é exata, elegante e cheia de graça. Preciso no manejo do idioma, o autor de Memórias póstumas de Brás Cubas tem uma inconfundível arte de narrar, de transmitir o mundo da sua apurada sensibilidade.

Da sua primeira infância, ignora-se se Machadinho, como era chamado, frequentou escolas; entretanto, sabemos que sua paixão pela palavra escrita foi precoce. Aos 10 anos, sabia de cor a Canção do exílio, de Gonçalves Dias.

Joaquim Maria Machado de Assis nasceu em uma chácara do Morro do Livramento, no Rio de Janeiro, a 21 de junho de 1839, e morreu na madrugada de 29 de setembro de 1908, na casa do Cosme Velho. Mulato e pobre, filho de um pintor de paredes e de uma lavadeira portuguesa dos Açores, revelou desde cedo uma saúde debilitada. Gago e epiléptico, o garoto conservaria por toda a vida um temperamento tímido e reservado. Não podendo estudar regularmente, o poeta de Falenas formou sua cultura como autodidata.

Em 1856, conseguiu emprego como aprendiz de tipógrafo na Imprensa Nacional. Conheceu o então diretor, Manuel Antônio de Almeida, autor já consagrado de Memórias de um sargento de milícias, que se tornou seu protetor. Em 1897, aplaudido como um dos maiores ficcionistas brasileiros, foi aclamado presidente perpétuo da Academia Brasileira de Letras.

No que diz respeito à sua obra, Machado de Assis cultivou praticamente todos os gêneros literários: romance, conto, poesia, crônica, teatro e crítica. Suas produções de maior importância encontram-se no romance (Memórias póstumas de Brás Cubas, Quincas Borba, Dom Casmurro, Esaú e Jacó e Memorial de Aires) e no conto (Missa do galo, A cartomante, $O$ espelho, Teoria do medalhão, O alienista, e tantos outros).

O cônego ou metafísica do estilo, originalmente publicado no jornal Gazeta de Notícias, em 22 de novembro de 1885, integra a coletânea Várias histórias, publicada em 1896, que reúne dezesseis contos publicados naquele jornal entre 1884 e 1891. 
Sobre nossa tradução do conto, gostaríamos de dizer que nos deparamos com inúmeras passagens intrincadas e interessantes do original cujo lidar gostaríamos de compartilhar com você leitor; escolhemos algumas delas para lhes apresentar.

A este ponto, gostaríamos de lhes aconselhar, cara leitora e caro leitor, as leituras prévias do conto e de nossa tradução, a fim de conhecerem o original e apreenderem nossos comentários de modo algo mais contextualizado.

De pronto afirmamos que nenhuma frase do conto poderia ser lida sem a devida atenção, sem deixar imperceptível algo de chamativo, rico, velado, algo subentendido, trazendo as preocupações e ideias do escritor. Fizemos nossas escolhas tradutórias ao longo das leituras do conto, e com o apoio de leituras paralelas sobre o autor e suas obras. Além disso, marcamos alguns encontros para discutirmos passagens textuais desafiadoras, tanto em relação à compreensão/interpretação do original quanto para a tomada de decisões referentes às nossas soluções pensadas para o público de língua e cultura alemãs.

Para estabelecer um guia para nosso trabalho, fizemos um projeto de tradução que se preocupou basicamente com duas questões. A primeira: queremos levar nosso leitor à obra original, escrita numa linguagem arcaica, e manter o estilo de Machado de Assis o máximo possível em alemão? Respondemos a essa pergunta com um “sim”, o que conduziu, em seguida, à segunda questão de nosso projeto, um preceito para a retextualização em vista: utilizar a Bíblia traduzida em alemão por Martinho Lutero (1912 [1530]) e buscar em obras de escritores como Johann Wolfgang von Goethe, Heinrich von Kleist, Gertrud Kolmar, Immanuel Kant e Siegmund Freud, expressões e vocábulos que pudessem vir a contribuir para a tessitura do texto em alemão.

Há um sopro bíblico claramente identificado no "Cônego". São várias as passagens e os vocábulos que nos remeteram à Bíblia. As primeiras linhas do conto, o diálogo do casal, "Vem do Líbano, esposa minha, vem do Líbano, vem... As mandrágoras deram o seu cheiro. Temos às nossas portas toda casta de pombos...”, Machado de Assis as retira dos "Cantares" de Salomão, tal como se lê na Bíblia traduzida em português por João Ferreira de Almeida (ou escrito de modo mais arcaico, Ioaõ Ferreira Annes d'Almeida ou Yoam Ferreira Annes d'Almeida, importante personalidade do protestantismo português). Em alemão, transcrevemo-las com palavras de Lutero: Komm mit mir vom Berge Libanon, meine Braut, komm mit mir vom Libanon, komm... Die Alraunen geben Duft, und an unseren Türöffnungen allerlei Tauben... (Hohelieder 4, 8). A mandrágora é uma planta da família das Solanaceae. São-lhe atribuídas propriedades medicinais, tais como atributos afrodisíacos, alucinógenos, analgésicos e narcóticos. Em 1503, Nicolau Maquiavel publica Mandrágora, uma peça de teatro que conta a história do jovem Calímaco, que deseja uma mulher casada. Para conquistá-la, ele finge ser médico e receita um tratamento à base de mandrágora. Maquiavel constrói um texto em que a conquista amorosa serve como pretexto para desenvolver um tratado sobre a arte de conquistar um objetivo. No caso de Machado, seu personagem, o cônego, sai à procura de um adjetivo que possa vir a se unir ao substantivo saído de sua pena. Como tradução, não optamos pelo vocábulo adotado pelo tradutor alemão da Bíblia (Gênesis 30, 14, e Cantares 7, 13), "Liebesbeeren” (frutinhas do amor), mas sim por "Alraunen” (mandrágora, em português). O motivo para essa decisão foi o fato de escolhermos uma linguagem com o estilo irônico do autor original. Uma tradução presa à linguagem bíblica não funcionaria. Machado não quis contar uma história de amor; ele cutuca a Igreja e o sistema de então. Alraune é uma frutinha utilizada em rituais 
mágicos - uma frutinha bastante venenosa -, e suas raízes parecem com a fisionomia humana. Por essa definição, achamos adequado introduzir esse termo ao conto para alertar o leitor atento que a viagem de Sílvio e Sílvia pode ser uma aventura alucinógena, inclusive.

Outro exemplo retirado da Bíblia é o trecho eingefasste Opal-wörter (letras de opala embutidas, de Fassungen, 2. Mose 39, 16 / Hohelieder 5, 14). Na tradução de João Ferreira, lemos: “... as suas mãos [são] cilindros de ouro, embutidos de jacintos”. Mais exemplos, encontramos nas seguintes passagens: Und alles wird vollendet sein ("e tudo estará acabado"; 2. Mose 39, 32), Kleingläubigkeit ("pouca fé”; Matthäus 6, 30), Irrwege ("circunvoluções"; Psalmen 95, 10), Botschaften ("recados”; Jeremia 20,15), finster (“obscuro"; Klagelieder 5, 17), Es [der Weg] wird immer enger ("o espaço estreita-se”; Jesaja 10, 29. No final do conto, citamos novamente trechos de Hohelieder "Wer ist die, die heraufsteigt von der Wüste und lehnt sich auf ihren Geliebten?” (Hohelieder 8, 5). "Es ist das Siegel Deines Herzens" e "die Liebe ist stark wie der Tod". (Hohelieder 8, 6). Em especial, no trecho "e tudo estará acabado" (und alles wird vollendet sein), deparamo-nos com certa ambiguidade; pois algo pode estar acabado, no sentido de destruído, ou acabado no sentido de pronto. A Bíblia nos desvendou essa ambiguidade com as palavras já mencionadas acima, optando pelo sentido de "pronto", “concluído”.

Outra palavra, cuja tradução nos deu bastante trabalho, foi a palavra “circunvoluções” ([...] vamos lá por essas circunvoluções do cérebro eclesiástico $[\ldots])$.

Nesse caso, a passagem bíblica dos Psalm 95, 10 nos ajudou com o verso [...] deren Herz immer den Irrweg will. "Irrwege" (descaminhos, transvios) também existem em labirintos, imagem que nos parece apropriada para o contexto do cérebro eclesiástico. De modo divertido lemos essas circunvoluções do cérebro eclesiástico, o substantivo à procura do adjetivo. Sílvio chama por Sílvia.

Caminho difícil e intrincado que é este de um cérebro tão cheio de cousas velhas e novas! Há aqui um burburinho de idéias, que mal deixa ouvir os chamados de ambos; não percamos de vista o ardente Sílvio, que lá vai, que desce e sobe, escorrega e salta; aqui, para não cair, agarra-se a umas raízes latinas, ali abordoa-se a um salmo, acolá monta num pentâmetro, e vai sempre andando, levado de uma força íntima, a que não pode resistir.

Welch ein schwerer und verzwickter Weg ist der eines Gehirns, voll von altem und neuem Zeug! Hier gibt es ein Getuschel von Gedanken, das ihre Rufe kaum erschallen lässt; lassen wir den feurigen Sílvio nicht aus den Augen, der da geht, mal runter mal hoch, rutscht und springt; hier, um nicht zu fallen, hält er sich an so manchen lateinischen Wurzeln fest, da stützt er sich auf einen Psalm, dort steigt er auf einen fünfsilbigen Vers und reitet immer weiter, von einer inneren Kraft getrieben, welcher er nicht widerstehen kann.

O erotismo presente nos "Cantares" perpassa também o conto, o que buscamos manter na narrativa em alemão; pensamos a tradução também a partir dos vestígios eróticos que ele comporta. Os dois princípios, o masculino e o feminino, procuram-se, operando um deslocamento das pulsões sexuais para a linguagem; “as palavras têm sexo”. Do ponto de vista da lógica da narração, Machado de Assis utiliza verbos no tempo passado, distanciando o narrador e, igualmente, o leitor. Para narrar o processo de criação do sermão, o tempo verbal predominante é o presente do 
indicativo; embora o tempo verbal do texto narrativo seja, em geral, o pretérito perfeito, aqui ele é justificado pelo propósito de o autor querer mostrar a composição do texto no momento de sua escritura. Procuramos manter também em alemão esse fluxo contínuo de reminiscências e experiências tecidos pelo narrador.

Expressões como "grupos de idéias" (Bündel von Ideen), "reminiscências da infância e do seminário" (Erinnerungen an die Kindheit und an die Klosterschule), "outras idéias, grávidas de idéias" (andere Ideen, schwanger von Ideen), refletem um quadro de pensamentos agitados, intensos e vertiginosos na cabeça do cônego; há uma enumeração de recordações e experiências, todas separadas por ponto-e-vírgula, como neste trecho:

Cousas e homens amalgamam-se; Platão traz os óculos de um escrivão da câmara eclesiástica; mandarins de todas as classes distribuem moedas etruscas e chilenas, livros ingleses e rosas pálidas; tão pálidas, que não parecem as mesmas que a mãe do cônego plantou quando ele era criança.

Dinge und Menschen werden eins; Platon bringt die Brille eines Schreibers des Kirchenvorstandes; Mandarins aller Klassen verteilen etruskische und chilenische Münzen, englische Bücher und blasse Rosen; so blass, dass sie nicht jenen gleichen, welche die Mutter des Domherrn einst pflanzte, als er ein Kind war.

Com a mesma pontuação adotada e as aliterações criadas, buscamos, tal qual no original, guiar o leitor, abrindo-lhe frestas na linguagem, permitindo-o adentrar no (in)consciente do cônego. Que nossos leitores possam degustar do livre-pensamento insurgente da pena de Machado de Assis. Com seu Realismo, o autor entabula uma conversa com seu leitor; partilha as ciências da sua realidade e o espírito do cientificismo da época, dialogando com o seu tempo e com o tempo do porvir. Numa estrutura metalinguística, o autor deixa o narrador anunciar sua teoria: "Não me interrompas, leitor precipitado; sei que não acreditas em nada que vou dizer." "Di-loei, contudo, a despeito da tua pouca fé, porque o dia da conversão pública há de chegar", Unterbrich mich nicht, voreiliger Leser; mir ist bewusst, dass Du dem, was ich sagen werde, keinen Glauben schenkst. Dennoch werde ich es Dir sagen, trotz Deiner Kleingläubigkeit, denn es wird kommen der Tag der öffentlichen Bekehrung. Em sua escritura, o contista deixa reverberar ecos das investigações dos processos inconscientes em voga nas pesquisas psicológicas europeias da época. Podemos falar, portanto, que na obra machadiana lemos uma espécie de antecipação da ideia de inconsciente, esboçada aqui com maestria:

Memórias pias familiares cruzam-se e confundem-se. Cá estão as vozes remotas da primeira missa; cá estão as cantigas da roça que ele ouvia cantar às pretas, em casa; farrapos de sensações esvaídas, aqui um medo, ali um gosto, acolá um fastio de cousas que vieram cada uma por sua vez, e que ora jazem na grande unidade impalpável e obscura.

Fromme und vertraute Erinnerungen begegnen sich und verwechseln sich. Da sind die Stimmen von damals, von der ersten Messe; da sind die Volkslieder vom Lande, die er von den schwarzen Frauen hörte, zu Hause; Fetzen geschwächter Empfindungen, hier Angst, da Freude, dort langweilige Dinge; von denen ein jedes nach und nach gekommen, und die nun in der großen, ungreifbaren und finsteren Einheit ruhen. 
A partir de tal passagem, tendo em mente a profícua interação possível entre a criação literária e as descobertas (ou criações?) da ciência, cabe lembrar uma declaração feita por Sigmund Freud em sua obra Delírios e sonhos na Gradiva de Wilhelm Jensen (Der Wahn und die Träume in W. Jensens Gradiva), de 1906:

[...] os escritores criativos são aliados muito valiosos, cujo testemunho deve ser levado em alta conta, pois costumam conhecer toda uma vasta gama de coisas entre o céu e a terra com as quais a nossa filosofia ainda não nos deixou sonhar. Estão bem diante de nós, gente comum, no conhecimento da mente, já que se nutrem em fontes que ainda não tornamos acessíveis à ciência. (FREUD, 1976, v.7, p.18).

Voltando ao parágrafo de Machado, é nesse palco (o inconsciente) que Sílvio e Sílvia se buscam, imbuídos na crença amorosa da completude entre ele, Sílvio, o substantivo, e ela, Sílvia, o adjetivo. É nos Cantares que o cônego busca sua inspiração. Outro exemplo em relação ao erotismo do conto é a expressão "tocados [os lábios] de febre”, que traduzimos por fieberglühend. Para criar essa palavra composta em alemão, fomos inspirados pelos versos de Gertrud Kolmar (HAHN: 1983, p. 14) de seu poema Verwandlungen, em que lemos o verbo glühen (arder) na estrofe onde aparece o tema da sedução pelos lábios. Outro trecho erótico no conto de Machado de Assis é o momento em que o narrador se refere ao "Sílvio ardente”. Em alemão, não traduzimos "ardente” por brennend ou glühend; consideramos o adjetivo feurig, que se costuma usar na fala alemã num contexto erótico.

Último exemplo desse naipe que gostaríamos de compartilhar com vocês, leitoras e leitores, é uma passagem que exigiu de nós considerável criatividade e pesquisa; “[...] cabelos cortados à cabeça do Sol ou da Noite; [...]." No contexto da procura da amada (do adjetivo), em que Machado descreve as outras (damas), no trecho citado, pensamos ser possível que o sol e a noite possam se referir às cores dos cabelos das outras damas. Essas cores podem ser o loiro dourado, goldschimmernd, ou a cor escura, dunkel wie die Nacht. Na Bíblia, em Jesaja 13,10, encontramos certas pistas para lidar com o léxico através do verso "[...] die Sonne geht finster auf, und der Mond scheint dunkel." O verbo scheinen (brilhar) faz a regência com o sol e implica que algo brilha ou reflete (schimmert) ao receber seus raios. O adjetivo dunkel (escuro) ficaria em relação à noite, à lua (Mond), que brilha também. A frase em alemão ficaria "[...] geschnittenes Haar, goldschimmernd oder dunkel wie die Nacht [...]”. Porém, para deixar o conto aberto à imaginação do leitor, optamos por deixar a passagem em alemão mais parecida com o original: "[...] geschnittenes Haar, hin zur Sonne oder zur Nacht [...]”".

A despeito da predominância de linguagem denotativa, o conto aponta palavras e expressões usadas conotativamente, com o uso de figuras de linguagem, como metáforas, por exemplo: “O paradoxo despirá as asas para vestir a japona de uma verdade comum.” Também verifica-se o uso de orações reduzidas, por exemplo, "a espairecer do esforço” (um sich von der Anstrengung zu erholen), quando buscamos o mesmo tipo de circunstância - se tempo, se fim - também em alemão.

A respeito dessa sensibilidade de querer tocar o leitor com a linguagem, a qual ele possa reconhecer e apreender, atribuindo às nossas palavras o devido sentido que cremos Machado pretendeu passar no conto original, mencionamos um conceito de Martinho Lutero sobre tradução; especialmente em situações da língua falada, sua visão sobre tradução nos auxilia. No Segundo Princípio da Carta aberta sobre tradução (LUTERO, 2006 [1530]), relata ele a importância da observação dos modos do 
homem comum usar a língua. Para poder traduzir, por exemplo, a expressão “Upa!”, recorremos aos livros de quadrinhos (comics) de Walt Disney em alemão, e assim achamos a interjeição "So! Da wären wir", que a nosso ver seria muito bem utilizada nesse contexto por um falante de alemão.

Num outro trecho, tivemos que trocar uma conjunção por um advérbio devido à obediência ao uso da língua pelos nativos; foi no trecho: "Dê-me a leitora a mão, agarre-se o leitor a mim, e escorreguemos também.” A conjunção “e” em alemão não soaria bem aqui se a traduzíssemos por und. Por isso, incluímos o advérbio modal (Modaladverb) so para deixar o texto coeso para o leitor alemão: Gib mir Deine Hand, meine Leserin, halte Dich fest an mir, mein Leser, so rutschen wir mit. Para citar mais um exemplo, incluímos um pequeno acréscimo em nossa tradução do trecho "Espaireceu à vontade, tornou à mesa do trabalho, e relê o que escreveu, para continuar [...]." Como mencionado anteriormente, Machado escreve com muitas mudanças de tempo verbal em seu conto, e na tradução desse trecho para o alemão (Er hatte sich genügend abgelenkt, kam zurück an den Schreibtisch, und liest nun noch einmal [...]), sem a inclusão do advérbio de tempo nun, a segunda oração causaria um estranhamento para o leitor com relação à fluência do texto. Outra mudança lexical que achamos necessária, seguindo a concepção de Lutero, diz respeito ao trecho "com grandes gestos de veneração" que traduzimos por mit Gesten größter Verehrung. Sem o superlativo größter (“maiores”, em vez de "grandes”), a nosso ver, a oração não teria soado bem em alemão.

Um dos maiores desafios tradutórios com que lidamos na reescritura do conto foi a expressão com diminutivo ao seu final: “e irão juntinhos ao prelo". Trabalhamos com o advérbio schön, em alemão, para engalanar o adjetivo "junto" (beieinander), dando-lhe a ideia de diminutivo, pois em língua alemã pode-se fazer o diminutivo somente dos substantivos.

Outro ponto gramatical que não queremos deixar de mencionar a respeito da língua falada são as partículas expletivas (Modalpartikel) utilizadas na língua alemã para deixar o texto, geralmente um diálogo, autêntico e natural. No conto, quando o autor conversa com seu leitor, fica indispensável, em alemão, fazer uso de certas partículas expletivas. Como exemplos, podemos citar a frase em português: "Matias sorriu manso e discreto, como devem sorrir os eclesiásticos e os diplomatas." As partículas expletivas wohl eben enfatizam nesta frase a farsa do sorriso dos eclesiásticos e dos diplomatas: Matias lächelte leicht und zurückhaltend, so wie die Geistlichen und Diplomaten wohl eben lachen sollen. Outro exemplo é a passagem em que o narrador convida o leitor para entrar na cabeça do cônego: "Pois entre aqui também na cabeça do cônego." Para enfatizar o convite pessoal e que o autor realmente quer que o leitor adentre a cabeça de nosso cônego, utilizamos a partícula expletiva doch: So kommen Sie doch auch hier herein in den Kopf des Domherrn. Último exemplo de partículas expletivas pode-se acompanhar na frase traduzida Aber Sílvio und Sílvia erinnern sich durchaus aneinander: "Mas Sílvio e Sílvia é que se lembram de si”. Para ressaltar a ênfase das partículas "é que” em alemão, cabe bem a partícula expletiva de intensidade (Intensitätspartikel) durchaus, no sentido de que Sílvio e Sílvia, eles sim se lembram muito bem um do outro.

\footnotetext{
1 Walt Disney, Lustiges Taschenbuch, der goldene Krieger, nr. 149, 1990, p. 94.
} 
Também ilustramos o uso do verbo modal müssen para traduzir "hão" na oração em português: "Hão de traduzi-la [a página] em todas as línguas.”, escrita no tempo verbal futuro. A tradução ficou In alle Sprachen wird sie übersetzt werden müssen, e o verbo modal müssen não deveria faltar aqui em alemão para enfatizar a certeza que o autor demonstra quando fala da importância de seus escritos.

Outro ponto gramatical considerado em nossa tradução é o uso da voz passiva em alemão. "Hão de traduzi-la em todas as línguas": In alle Sprachen wird sie übersetzt werden müssen. E a oração "Vieram encomendar-lhe o sermão para certa festa próxima": Er war beauftragt worden, die Predigt für ein bestimmtes bevorstehendes Fest zu verfassen. Em ambos os exemplos enquanto em português podemos omitir o sujeito da frase, em alemão, por se desconhecer o sujeito, optamos pela voz passiva.

Em termos estruturais, mantivemos a sintaxe da tradução obedecendo à gramática do alemão para não causar estranhamento na leitura; porém, em relação à pontuação, seguimos a de Machado de Assis, na medida em que esta se presta, também em alemão, para a reconstituição do ritmo e do estilo do original. Por sua vez, fizemos duas alterações no período "As tiras saem-lhe das mãos, animadas e polidas. Algumas trazem poucas emendas ou nenhumas": Die Zeilen schreibt er an einem Stück, lebhaft und glänzend, manche bedürfen weniger Ausbesserungen, oder gar keiner. Enquanto em português depois de animadas e polidas (lebhaft und glänzend) há um ponto, em alemão optamos por uma vírgula para deixar o texto fluente e coeso, pois se mantivéssemos o ponto, faltaria um verbo na frase em alemão. Em relação à temática das tiras que lhe saem das mãos, a vírgula também dá mais movimento à frase. Nesse mesmo sentido, do fluxo da narração, também optamos por mudar a pontuação no final do conto, em que "Enfim, Sílvio achou Sílvia.” Em alemão, trocamos a vírgula por dois pontos para indicar o encontro do substantivo e do adjetivo - a procura chegou ao seu termo, o encontro, por fim, realizou-se. Endlich: Sílvio fand Sílvia.

Um ponto estrutural que modificamos em alguns trechos foi a substituição da oração relativa em português por uma oração subordinada em alemão; por exemplo na frase “[...] pó que tens de ser pirâmide [...] ”, em alemão [...] Staub, zur Pyramide verbannt, [...]. Em língua alemã, mesmo sem a oração relativa, a oração subordinada consegue se referir ao substantivo "pó” através do particípio verbannt. Na oração relativa em alemão, o verbo conjugado é colocado no final da sentença, e a sintaxe desse tipo de frase cortaria o ritmo em nossa tradução.

Certas palavras, que no português machadiano são de extrema riqueza, significaram perdas em nossa tradução, por não termos achado um referente em língua alemã. Como exemplos, podemos citar o substantivo “cousas”, a locução “à laia de”, o substantivo “japona”, usado como metáfora, e a expressão "entornar os olhos”. A metáfora com "japona” - “O paradoxo despirá as asas para vestir a japona de uma verdade comum” - aponta para o humor e a ironia, constantes nas obras de Machado de Assis. Em meio ao arsenal linguístico machadiano, a escolha aparentemente estapafúrdia por “japona” foi tema constante de nossas conversas, até conseguirmos achar um vocábulo em alemão que pudesse expressar esse tipo de vestuário feito, em geral, de tecido impermeável, com forro interno, que no Brasil popularizou-se, sendo vendido, em geral, nas grandes lojas a preços módicos; uma roupa nada especial, à qual o autor se refere para falar da "verdade comum". Inicialmente, optamos pelo substantivo no plural Klamotten (em português, roupas, trapos), que em alemão refere-se mormente a peças de roupas velhas, como em Klamottenkiste, que significa 
um baú com roupas velhas e empoeiradas. ${ }^{2}$ Pensamos também em Kleider (roupas), mas consideramos o substantivo por demais geral; por fim, ficamos com o substantivo Mantel (sobretudo, casaco, manto), que, tal como uma "japona”, traduz também a ideia de proteção e calor, e que, feito asas (Flügel), envolve, abraça.

Compensando algumas perdas na nossa tradução, buscamos palavras sonoras, com as quais pudéssemos criar aliterações possíveis. Aqui, algumas aliterações que, certamente, os leitores da tradução já devem ter percebido: a) [...] dass ich vor Liebe krank liege $[\ldots] ;^{3}$ b) [...] wiederholt ihm die gewohnten Wörter [...]; c) Sílvio und Sílvia sprießen zwischen Embrios und Ruinen. d) Sie lieben sich und sie suchen sich. Sie suchen sich und sie finden sich. e) Dabei bebt $\underline{\text { der }}$ Domherr.

Outras escolhas tradutórias quanto a vocábulos e expressões foram garimpadas nos textos de outros autores. Citamos, a seguir, alguns deles. De Johann Wolfgang von Goethe ganhamos duas "dicas". Ambas vêm de seu famoso poema "Der Erlkönig" (1782), o qual nos forneceu o adjetivo düster para traduzir os "pesares sombrios" (düsterer Kummer) do cônego, além de nos inspirar a traduzir o gerúndio "vai sempre andando" por reitet immer weiter, como o faz o pai do menino nesse poema dramático. Em um dos parágrafos, em que o narrador faz do leitor o seu interlocutor, onde lemos "Cambaleias, leitor? Não é o mundo que desaba [...]", valemo-nos de um dos escritos de Heinrich von Kleist, a saber, o conto Das Erdebeben in Chili (O terremoto do Chile), e, a partir daí, entendemos o "desmoronamento" ou “desabamento" machadiano como einstürzen:

Der Boden wankte unter seinen Füßen, alle Wände des Gefängnisses rissen, der ganze Bau neigte sich, nach der Straße einzustürzen, und nur der seinem langsamen Fall begegnende Fall des gegenüberstehenden Gebäudes verhinderte, durch eine zufällige Wölbung, die gänzliche Zubodenstreckung desselben. ${ }^{5}$

O chão balançava sob seus pés, todas as paredes da prisão racharam, o edifício inteiro inclinou-se, desmoronando na rua, e só a queda lenta do edifício em frente impediu, com a formação acidental de uma abóbada, o desmoronamento inteiro da construção. ${ }^{6}$

Outras palavras que nos deram considerável trabalho e que nos levaram a pedir ajuda à interpretação de estudiosos no assunto foram as palavras "inspiração" e “meditação”. Há vários sinônimos para cada uma delas em diversos contextos. José Maurício da Silva ${ }^{7}$ nos explica o significado dessas duas palavras "nos dois planos que se conciliam no processo criativo do cônego" (SILVA, 2005); o primeiro se refere ao "transcendente, à imaginação livre, ao inconsciente"; o segundo, ao "imanente, ao raciocínio e à consciência”; daí achamos os referentes em alemão: Inspiration e Besinnung.

2 http://www.duden.de/suchen/dudenonline/klamotten

3 Há dois trechos na Bíblia em que a palavra "enfermo" aparece no contexto do conto; em Hohelieder 5, 8, a frase termina em krank liege vor Liebe, e, em Hohelieder 2, 5, ela termina em Ich bin krank vor Liebe.

4 http://www.textlog.de/18455.html

5 Kleist, Heinrich von. Das Erdbeben in Chili. In: Sämtliche Werke. Berlin und Darmstadt: Deutsche Buch-Gemeinschaft, 1952, p. 718.

6 Tradução nossa.

7 http://www.ciencialit.letras.ufrj.br/garrafa5/10.html 
Por fim, o título. Pensamos, primeiramente, em criar uma palavra composta, como na ciência: Stil-Metaphysik; essa palavra, porém, pareceu-nos não traduzir o que é tratado no conto. Por sua vez, o filósofo alemão Immanuel Kant (1724-1804) denomina uma de suas obras de Metaphysik der Natur (Metafísica da natureza), o que nos levou ao título da nossa presente tradução, Metaphysik des Stils, e que, coincidência ou não, apresenta uma aliteração com a consoante "s".

Para nós tradutores, a tarefa de traduzir um conto do grande Machado de Assis significou, desde o início, um imenso desafio. Exercitar a compreensão em detalhe da presente obra em português, com algum sucesso, já consideramos uma vitória, o que só se concretizou ao longo de leituras repetitivas e conversas entre nós e com nossos interlocutores. Depois, tentar traduzir o conto elaborado, belo e fluido deste autor ímpar para outro sistema linguístico e cultural pareceu-nos, no primeiro olhar, uma tarefa difícil de ser levada a cabo. Mas ao longo de nossos encontros e pesquisas, tentamos entrar no mundo das letras da época em que o conto foi escrito, mergulhando na literatura alemã, respectivamente. E logo nos deparamos com o fascínio por fazer aquilo, uma vontade de conseguir reconstruir a obra desse grande escritor brasileiro também no universo de expressão alemã.

Com nossa tradução pretendemos fazer uma pequena homenagem a um autor admirável, e esperamos que nossos leitores possam degustar nosso propósito tradutório. Desejamos a todos uma leitura e viagem prazerosas!

Nossos agradecimentos pelo apoio e pelas preciosas contribuições vão ao grupo da $2^{\mathrm{a}}$ Oficina de Tradução Literária, da Professora doutora Rosvitha Friesen Blume (UFSC), com participação especial da tradutora Kristina Michahelles, ao Professor doutor Werner Heidermann (UFSC), ao Professor doutor Hans-Christian Trepte (Universität Leipzig), à Professora doutora Meta Elisabeth Zipser (UFSC), à mãe e amiga Clarice Amaral Richter e ao amigo e amante das letras Miguel Burg Demay. Ao Professor doutor Markus Weininger (UFSC), nossa gratidão pelas críticas construtivas, que são de extrema importância em um processo tradutório. E não poderíamos deixar de mencionar nosso inestimável editor Gustavo Althoff pela atenção dedicada.

\author{
Cássia Sigle \\ siglecassia@hotmail.com \\ Mestranda - Pós-Graduação em Estudos da Tradução, \\ Universidade Federal de Santa Catarina
}

Marcus Tulius Franco Morais ugrino2000@bol.com.br

Doutorando - Pós-Graduação em Estudos da Tradução, Universidade Federal de Santa Catarina 


\section{Referências}

BÍBLIA. A Bíblia Sagrada. Tradução de João Ferreira de Almeida. Rio de Janeiro: Sociedade Bíblica do Brasil, 1969.

FREUD, Sigmund. Delírios e sonhos na Gradiva de Jensen [1906]. In: Edição standard brasileira das obras psicológicas completas. Rio de Janeiro: Imago, 1976, v. 9, p. 11-95.

GOETHE, Johann Wolfgang von. "Erlkönig” [1782]. In: Goethes Werke. $1^{\mathrm{a}}$ ed. Gütersloh: Bertelsmann, s. a., p.104. Disponível em: $<$ http://www.textlog.de/18455.html>. Acesso em: 15 novembro 2013.

HAHN, Ulla (org.). Gertrud Kolmar Gedichte. München: Suhrkamp, 1983.

KLEIST, Heinrich von. Das Erdbeben in Chili. In: Sämtliche Werke. Berlin und Darmstadt: Deutsche Buch-Gemeinschaft, 1952, p. 718.

LUTERO, M. Carta aberta sobre a tradução. Tradução de Mauri Furlan. In: FURLAN, M. (org), Clássicos da Teoria da Tradução. Antologia bilíngue, vol. 4, Florianópolis: Núcleo de Tradução/UFSC. 2006.

LUTHER, Martin. Die Bibel. Stuttgart: Deutsche Bibelgesellschaft, 1912.

MACHADO DE ASSIS, Joaquim Maria. O Cônego ou Metafísica do Estilo. In: Obras Completas. Rio de Janeiro: Nova Aguilar, 2.ed, v. 2: Várias histórias, 2008, p. 528-532.

MAQUIAVEL, Nicolau. A Mandrágora. São Paulo: Abril Cultural, 1976.

MEYER, Augusto. A forma secreta. 4. ed., Rio de Janeiro: Francisco Alves, 1965.

SILVA, José Maurício da. A criação artística, sob a ótica de dois contos de Machado de Assis. Programa de Pós-Graduação em Ciência da Literatura, Letras-UFRJ. Revista Garrafa, ed. n. 5, janeiro-abril, 2005. Disponível em: $<$ http://www.ciencialit.letras.ufrj.br/garrafa5/10.html>. Acesso em: 20 novembro 2013. 